\title{
EFFECT OF INFILL TYPE AND DENSITY ON TENSILE PROPERTIES OF PLA MATERIAL FOR FDM PROCESS
}

\author{
Adi Pandzic, Damir Hodzic \& Aleksa Milovanovic
}
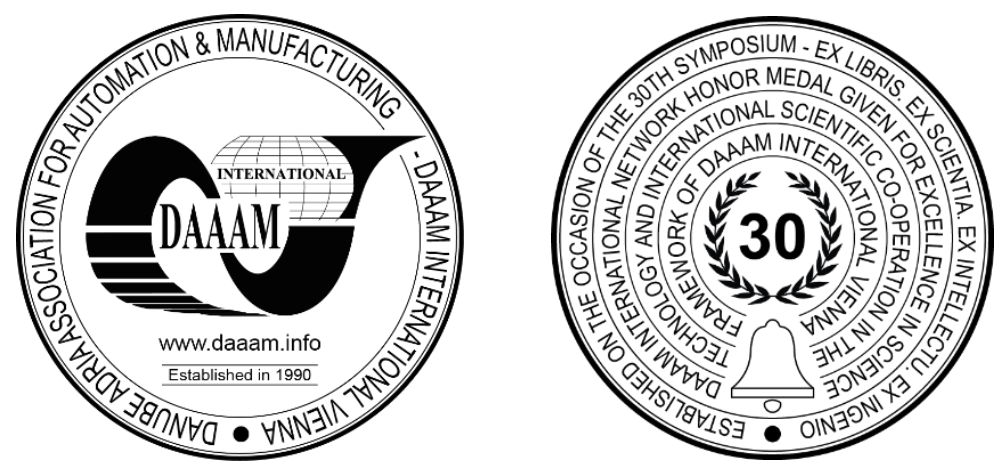

This Publication has to be referred as: Pandzic, A[di]; Hodzic, D[amir] \& Milovanovic, A[leksa] (2019). Effect of Infill Type and Density on Tensile Properties of PLA Material for FDM Process, Proceedings of the 30th DAAAM International Symposium, pp.0545-0554, B. Katalinic (Ed.), Published by DAAAM International, ISBN 978-3-90273422-8, ISSN 1726-9679, Vienna, Austria

DOI: $10.2507 / 30$ th.daaam.proceedings.074

\begin{abstract}
Fused deposition modeling (FDM) is a rapidly growing additive manufacturing technology for various applications in field of engineering. Mechanical properties of 3D printed materials in FDM technology depend on various parameters. Literature suggests that type and density of infill are parameters that affecting the mechanical properties of 3D printed materials, and also have direct influence on 3D printing time and amount of 3D printed material. In this paper influence of infill type and density on tensile properties, 3D printing time and amount of 3D printed material will be investigated and presented. Total of 13 different types of infill and for every type it will be tested 9 specimens with different infill density from $10 \%$ to $90 \%$. Every specimen would be 3D printed of PLA material with same colour and 3D printing parameters, also at the same position on printer bed to maximally reduce influence of other factors on mechanical properties of material. The obtained results would give us a wider picture of how to maximally save on 3D printing time and amount of material consumed in the production, but to still keep required tensile properties.
\end{abstract}

Keywords: Material; Infill; PLA; FDM; 3D Print

\section{Introduction}

Additive Manufacturing (AM), known as 3D print, is a group of technologies and processes that produce objects from a CAD model by adding layers of material bottom-up. AM is used in the manufacturing of prototypes (Rapid Prototyping), tools (Rapid Tooling) and final functional parts (Rapid Manufacturing). These technologies provide the ability to produce complex product geometries without the need of complex tooling. AM is gaining importance in the industry 4.0, and producing parts via this method offers many advantages over traditional manufacturing technologies [1], [2], [3]:

- Manufacturing of parts with high customization;

- Fabrication of a complex shapes from large variety of materials;

- Low cost and easy application;

- Great reduction in overall product development;

- On-demand manufacturing;

- High potential to approach zero waste manufacturing material compared to conventional subtractive technologies. 
The additive manufacturing technology is widely used in engineering for customized products, functional models, pre-surgical models and conceptual models. This technology finds its application in many fields of engineering and industry, such as automotive products (companies like Ford and Volkswagen), aircraft, dental restorations, medical implants (prosthetics, bionics, orthotics) and more. Today, designers and production engineers face the challenge of producing products faster than ever to meet customer requirements and fulfil their expectations [4], [5].

The increased use of 3D printing as a learning tool and to generate functional end-use parts in industry have generated need for a better understanding of the mechanical behaviour of 3D printed parts and the development of analytical tools and design guidelines for engineers. Materials testing of 3D printed plastics was performed in order to provide both industrial and academic communities with new to improve mechanical and digital design in the context of additive manufacturing; specifically fused deposition modelling (FDM) [6].

There are many different AM technologies today, and one of the more representative AM technology is FDM, layerforming technology by extrusion of wire-shaped materials. The FDM process is also known as "Material Extrusion" or FFF (Fused Filament Fabrication) process. First step in FDM process is to create STL file from 3D CAD model, and then in slicer software (eg Ultimaker Cura) create G-code with 3D printing parameters for 3D printer. The process of 3D printing with FDM technology consists of pushing a thermoplastic filament using and extruder element into a fusion chamber, known as a hotend. Then is heated to a semi-liquid state by heater block, in head of the printer, and pressed through the nozzle to build plate (printing bed). After the entire layer is applied, the pad is reduced by the thickness of the layer in the vertical axis and the gradual deposition continues again until the full product is formed. Shematic model of FDM process is presented on Fig 1 [2], [7], [8].

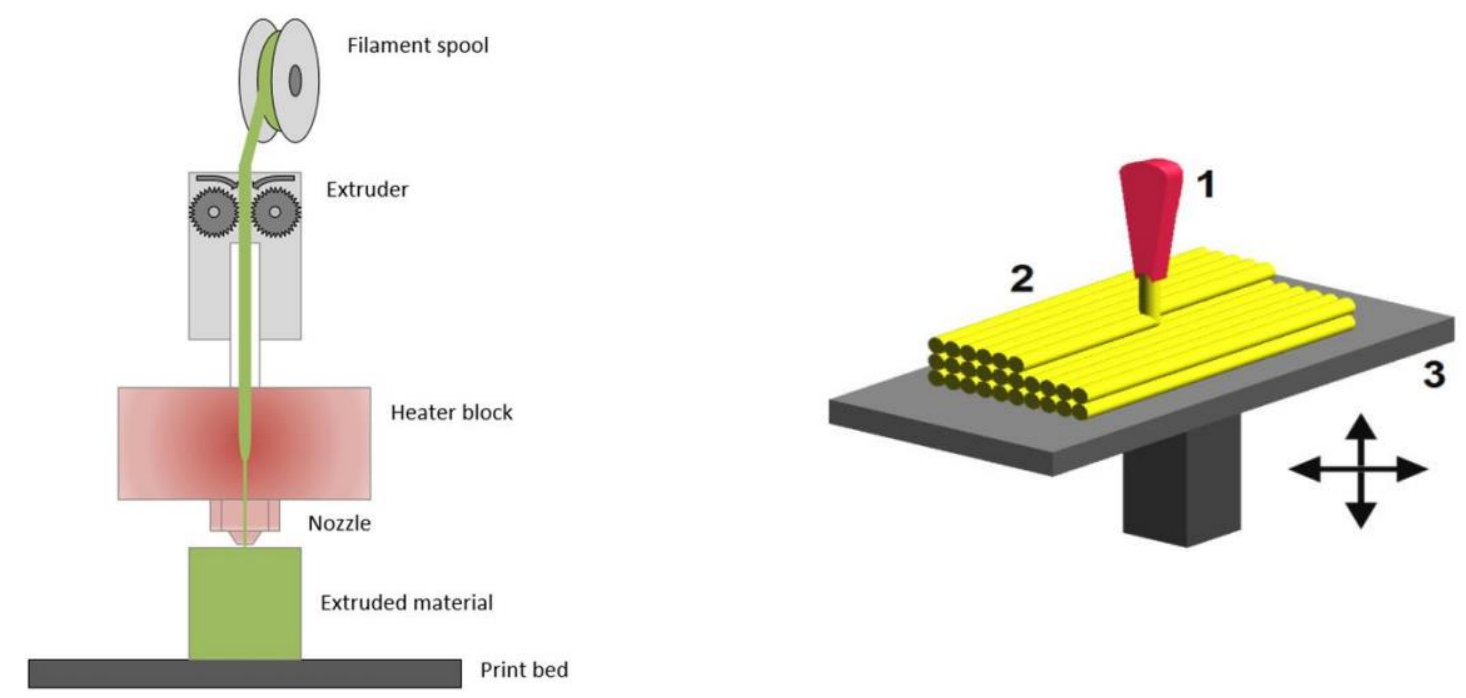

Fig. 1. Shematic model of FDM process (1-nozzle, 2-building material, 3-print bed) [2], [9]

Mechanical properties, tolerances and quality of finished product by FDM process depends on many parameters and factors. Software for preparing 3D CAD model for 3D printing, known as "slicers", allowing us to change many printing parameters that will affect on mechanical properties of product material (Fig 2). These parameters include printing temperature, build direction, raster orientation, layer height, extrusion width, infill pattern, infill density, number of shells, distance between nozzle and build plate, etc. Beside those parameters, there are also influence of environment factors (temperature, humidity) and material properties before printing [10], [11], [12].

From literature review, it is clear that infill pattern and density have direct influence on mechanical properties of material. Also, it is known that 3D printing companies through updates of their slicer softwares (eg. Ultimaker Cura) give their users to select new infill pattern, but without much details about their influence on final product. Ultimakers 3D Printing slicer "Cura" today have 13 different infill patterns.

As it is already mentioned, one of the benefits of FDM technology is large variety of materials. Today we have many different FDM material manufacturers, and most of them are thermoplastics, but there are also reinforced thermoplastics with carbon or fiberglass. There are many materials for FDM today on market, and some of them are PLA (polylactic Acid), ABS (Acrylonitrile Butadiene Styrene), PET (Polyethylene Terephthalate), nylon, PC (Polycarbonate), PEI (Polyetherimide, Ultem 9085) and more others. PLA became a popular FDM material, and thus also became a research topic of this paper.

Aim of this paper is to investigate the influence of infill pattern and density on mechanical properties of PLA material. Also, as known, infill pattern and density have influence on 3D printing time and amount of spent material (weight of product) and with this it have direct influence on product cost. In further work, total of 13 different infill patterns will be tested, and for every pattern we will test 9 different infill density (from $10 \%$ to 90\%). As filament, PLA material will be used with the same colour and from same manufacturer. 


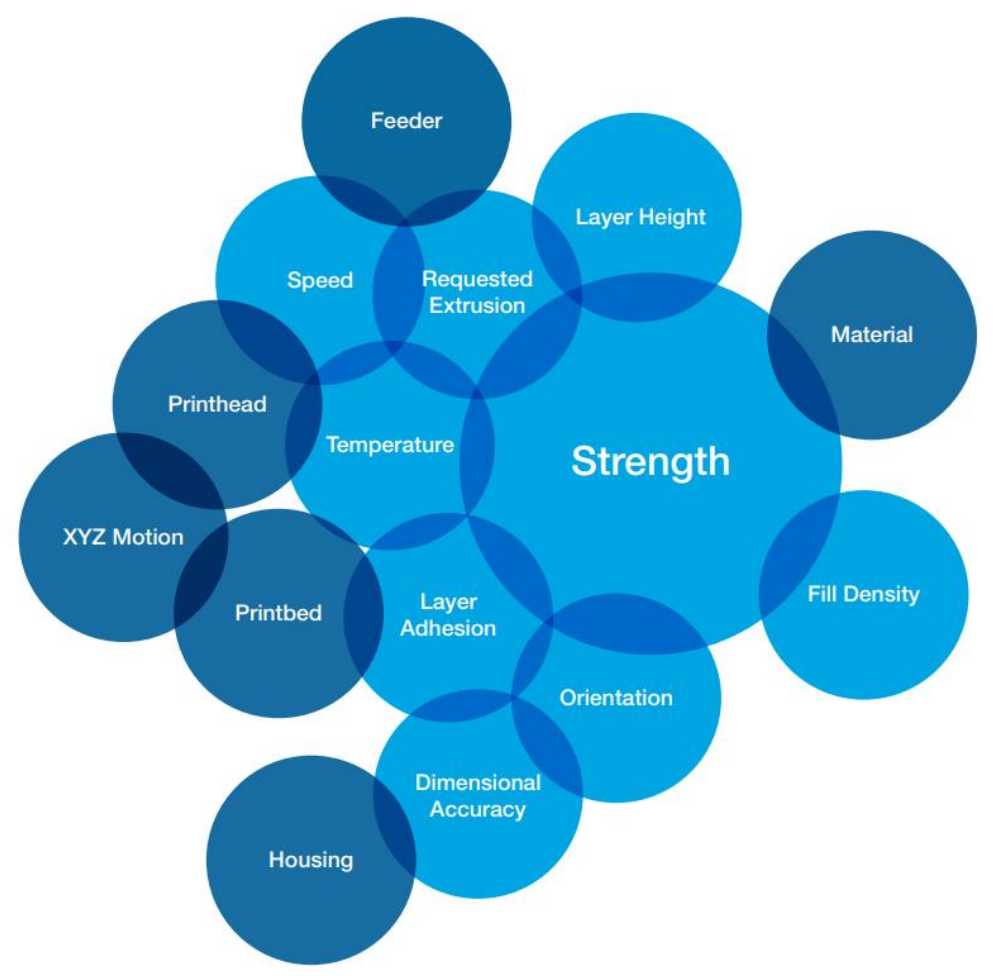

Fig. 2. Parameters that influence on strength of FDM 3D printed material [13]

\section{Experimental research and methodology}

This paper aims to examine the impact of infill pattern and density on mechanical properties of PLA material, also to analyse influence on printing time and costs. PLA material is chosen from manufacturer 3D Republika and diameter of filament wire is $2,85 \mathrm{~mm}$, a standard size for Ultimaker $2+3 \mathrm{D}$ printer. A dogbone-type specimen was chosen for the tests due to the simplicity of sample preparation and its suitability for FDM preparation. 3D model of dogbone-type specimen, according to ISO 527-2, was designed in Solidworks, also 3D model in STL format is prepared (Fig. 3).

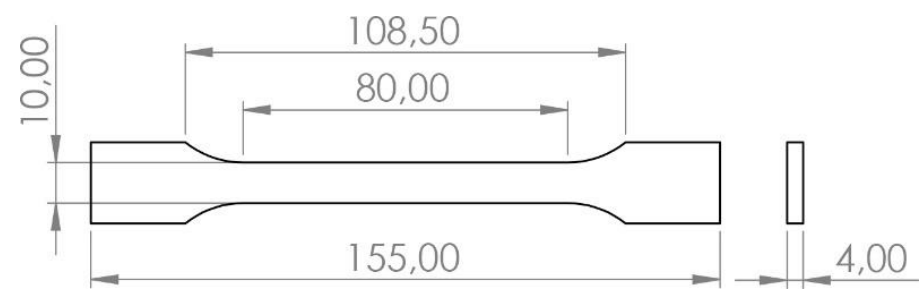

Fig. 3. Dogbone-type specimen according to ISO 527-2

A series of specimens were produced using an Ultimaker 2+ FDM 3D printer. Regarding the software and printing configurations, the toolpath calculation (G-code) was made with the Ultimaker's software Cura, version 4.0.0. Printing parameters were set by selecting the predefined "Normal" profile provided by the Cura. Methodology of preparing 3D model and 3D printing specimens is presented in Fig. 4.
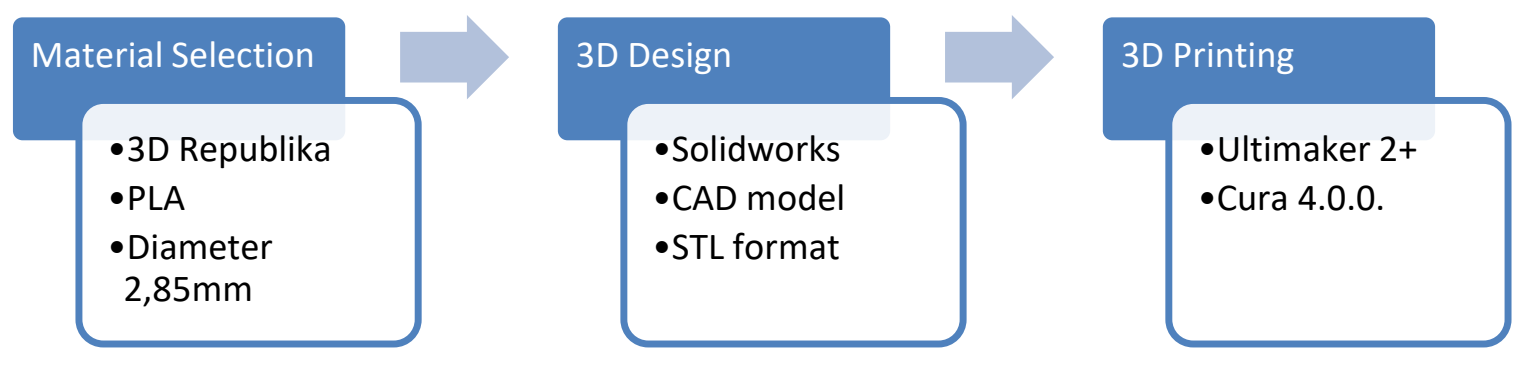

Fig. 4. Methodology of preparing 3D model and 3D printing specimens 
Main selected 3D printing parameters (predefined for normal profile) like nozzle diameter, layer height, infill density, wall thickness, print speed, printing and build plate temperature, and PLA material properties by manufacturer are presented in table 1 .

\begin{tabular}{|c|c|c|c|}
\hline \multicolumn{2}{|c|}{ Main 3D printing parameters } & \multicolumn{2}{c|}{ PLA material properties by manufacturer } \\
\hline Description & Value & Description & Typical value \\
\hline Nozzle diameter & $0,4 \mathrm{~mm}$ & Filament (wire) diameter & $2,85 \mathrm{~mm}$ \\
\hline Layer height & $0,15 \mathrm{~mm}$ & $\begin{array}{c}\text { Tensile Strength at Yield } \\
\text { (MPa) }\end{array}$ & $70 \mathrm{MPa}$ \\
\hline Wall thickness & $0,7 \mathrm{~mm}$ & Strain at yield & $5 \%$ \\
\hline Infill density & $100 \%$ & Strain at break & $2 \%$ \\
\hline Print speed & $60 \mathrm{~mm} / \mathrm{s}$ & E-Modulus & $3120 \mathrm{MPa}$ \\
\hline Printing temperature & $200{ }^{\circ} \mathrm{C}$ & $\begin{array}{c}\text { Impact strength }- \text { Charpy } \\
\text { method } 23^{\circ} \mathrm{C}\end{array}$ & $3,4 \mathrm{~kJ} / \mathrm{m}^{2}$ \\
\hline Build plate temperature & $60{ }^{\circ} \mathrm{C}$ & Printing temperature & $205 \pm 10^{\circ} \mathrm{C}$ \\
\hline Line width & $0,35 \mathrm{~mm}$ & Melting temperature & $115 \pm 35^{\circ} \mathrm{C}$ \\
\hline
\end{tabular}

Table 1. Main 3D printing parameters and PLA material properties by manufacturer

In this study, for experiment, specimens in 13 different infill patterns are printed, and for every pattern the infill density changed from $10 \%$ do $100 \%$. In the following table, all types of infill patterns are listed and displayed. Also, for each infill pattern and density, the time of 3D printing and the amount of material consumed per specimen are presented.

\begin{tabular}{|c|c|c|c|c|c|c|c|c|c|c|c|}
\hline Infill type & \multicolumn{11}{|c|}{ Grid } \\
\hline Infill denisty & $10 \%$ & $20 \%$ & $30 \%$ & $40 \%$ & $50 \%$ & $60 \%$ & $70 \%$ & $80 \%$ & $90 \%$ & $100 \%$ & \\
\hline 3D Printing time [min] & 46 & 49 & 52 & 55 & 57 & 60 & 62 & 64 & 66 & 93 & \\
\hline Approx material $[\mathrm{g}]$ & 7 & 7 & 8 & 8 & 9 & 9 & 10 & 10 & 11 & 12 & \\
\hline Infill type & \multicolumn{11}{|c|}{ Lines } \\
\hline Infill denisty & $10 \%$ & $20 \%$ & $30 \%$ & $40 \%$ & $50 \%$ & $60 \%$ & $70 \%$ & $80 \%$ & $90 \%$ & $100 \%$ & \\
\hline 3D Printing time [min] & 46 & 49 & 52 & 55 & 57 & 60 & 62 & 65 & 67 & 93 & \\
\hline Approx material $[\mathrm{g}]$ & 7 & 7 & 8 & 8 & 9 & 9 & 10 & 10 & 11 & 12 & \\
\hline Infill type & \multicolumn{11}{|c|}{ Triangles } \\
\hline Infill denisty & $10 \%$ & $20 \%$ & $30 \%$ & $40 \%$ & $50 \%$ & $60 \%$ & $70 \%$ & $80 \%$ & $90 \%$ & $100 \%$ & \\
\hline 3D Printing time [min] & 46 & 49 & 52 & 55 & 57 & 60 & 62 & 65 & 68 & 93 & \\
\hline Approx material $[\mathrm{g}]$ & 7 & 7 & 8 & 8 & 9 & 9 & 10 & 10 & 11 & 12 & \\
\hline Infill type & \multicolumn{11}{|c|}{ Tri-Hexagon } \\
\hline Infill denisty & $10 \%$ & $20 \%$ & $30 \%$ & $40 \%$ & $50 \%$ & $60 \%$ & $70 \%$ & $80 \%$ & $90 \%$ & $100 \%$ & \\
\hline 3D Printing time [min] & 46 & 49 & 51 & 54 & 56 & 59 & 62 & 64 & 67 & 93 & \\
\hline Approx material $[\mathrm{g}]$ & 7 & 7 & 8 & 8 & 9 & 9 & 10 & 10 & 11 & 12 & \\
\hline Infill type & \multicolumn{11}{|c|}{ Cubic } \\
\hline Infill denisty & $10 \%$ & $20 \%$ & $30 \%$ & $40 \%$ & $50 \%$ & $60 \%$ & $70 \%$ & $80 \%$ & $90 \%$ & $100 \%$ & \\
\hline 3D Printing time [min] & 46 & 49 & 52 & 54 & 57 & 59 & 62 & 65 & 67 & 93 & \\
\hline Approx material [g] & 7 & 7 & 8 & 8 & 9 & 9 & 10 & 10 & 11 & 12 & \\
\hline Infill type & \multicolumn{11}{|c|}{ Cubic Subdivision } \\
\hline Infill denisty & $10 \%$ & $20 \%$ & $30 \%$ & $40 \%$ & $50 \%$ & $60 \%$ & $70 \%$ & $80 \%$ & $90 \%$ & $100 \%$ & \\
\hline 3D Printing time [min] & 46 & 48 & 50 & 52 & 54 & 56 & 59 & 61 & 62 & 93 & \\
\hline Approx material $[\mathrm{g}]$ & 6 & 7 & 7 & 8 & 8 & 9 & 9 & 10 & 10 & 12 & \\
\hline Infill type & \multicolumn{11}{|c|}{ Octet } \\
\hline Infill denisty & $10 \%$ & $20 \%$ & $30 \%$ & $40 \%$ & $50 \%$ & $60 \%$ & $70 \%$ & $80 \%$ & $90 \%$ & $100 \%$ & \\
\hline 3D Printing time [min] & 46 & 49 & 52 & 54 & 57 & 60 & 62 & 64 & 67 & 93 & \\
\hline Approx material $[\mathrm{g}]$ & 7 & 7 & 8 & 8 & 9 & 9 & 10 & 10 & 11 & 12 & \\
\hline Infill type & \multicolumn{11}{|c|}{ Quarter Cubic } \\
\hline Infill denisty & $10 \%$ & $20 \%$ & $30 \%$ & $40 \%$ & $50 \%$ & $60 \%$ & $70 \%$ & $80 \%$ & $90 \%$ & $100 \%$ & \\
\hline 3D Printing time [min] & 46 & 49 & 52 & 55 & 57 & 60 & 62 & 64 & 67 & 93 & \\
\hline Approx material $[\mathrm{g}]$ & 7 & 7 & 8 & 8 & 9 & 9 & 10 & 10 & 11 & 12 & \\
\hline Infill type & \multicolumn{11}{|c|}{ Concentric } \\
\hline
\end{tabular}




\begin{tabular}{|c|c|c|c|c|c|c|c|c|c|c|}
\hline Infill denisty & $10 \%$ & $20 \%$ & $30 \%$ & $40 \%$ & $50 \%$ & $60 \%$ & $70 \%$ & $80 \%$ & $90 \%$ & $100 \%$ \\
\hline 3D Printing time [min] & 45 & 47 & 50 & 53 & 55 & 58 & 60 & 63 & 65 & 93 \\
\hline Approx material [g] & 6 & 7 & 7 & 8 & 9 & 9 & 10 & 10 & 11 & 12 \\
\hline Infill type & \multicolumn{10}{|c|}{ Zig Zag } \\
\hline Infill denisty & $10 \%$ & $20 \%$ & $30 \%$ & $40 \%$ & $50 \%$ & $60 \%$ & $70 \%$ & $80 \%$ & $90 \%$ & $100 \%$ \\
\hline 3D Printing time [min] & 46 & 49 & 51 & 54 & 56 & 59 & 61 & 64 & 66 & 93 \\
\hline Approx material [g] & 7 & 7 & 8 & 8 & 9 & 9 & 10 & 10 & 11 & 12 \\
\hline Infill type & \multicolumn{10}{|c|}{ Cross } \\
\hline Infill denisty & $10 \%$ & $20 \%$ & $30 \%$ & $40 \%$ & $50 \%$ & $60 \%$ & $70 \%$ & $80 \%$ & $90 \%$ & $100 \%$ \\
\hline 3D Printing time [min] & 47 & 49 & 53 & 58 & 61 & 68 & 71 & 76 & 83 & 93 \\
\hline Approx material [g] & 7 & 7 & 7 & 8 & 8 & 9 & 9 & 10 & 10 & 12 \\
\hline Infill type & \multicolumn{10}{|c|}{ Cross 3D } \\
\hline Infill denisty & $10 \%$ & $20 \%$ & $30 \%$ & $40 \%$ & $50 \%$ & $60 \%$ & $70 \%$ & $80 \%$ & $90 \%$ & $100 \%$ \\
\hline 3D Printing time [min] & 47 & 50 & 53 & 56 & 59 & 63 & 66 & 69 & 74 & 93 \\
\hline Approx material [g] & 7 & 7 & 7 & 8 & 8 & 8 & 9 & 9 & 10 & 12 \\
\hline Infill type & \multicolumn{10}{|c|}{ Gyroid } \\
\hline Infill denisty & $10 \%$ & $20 \%$ & $30 \%$ & $40 \%$ & $50 \%$ & $60 \%$ & $70 \%$ & $80 \%$ & $90 \%$ & $100 \%$ \\
\hline 3D Printing time [min] & 47 & 49 & 53 & 56 & 63 & 67 & 72 & 78 & 83 & 93 \\
\hline Approx material [g] & 7 & 7 & 8 & 8 & 9 & 9 & 10 & 10 & 11 & 12 \\
\hline
\end{tabular}

Table 2. Infill patterns, 3D printing time and amount of material per specimen

Total of 130 specimens are 3D printed for testing. Each specimen was printed under the same conditions, with "flat" printing orientation and $45^{\circ}$ raster angle, shown on Fig. 5.
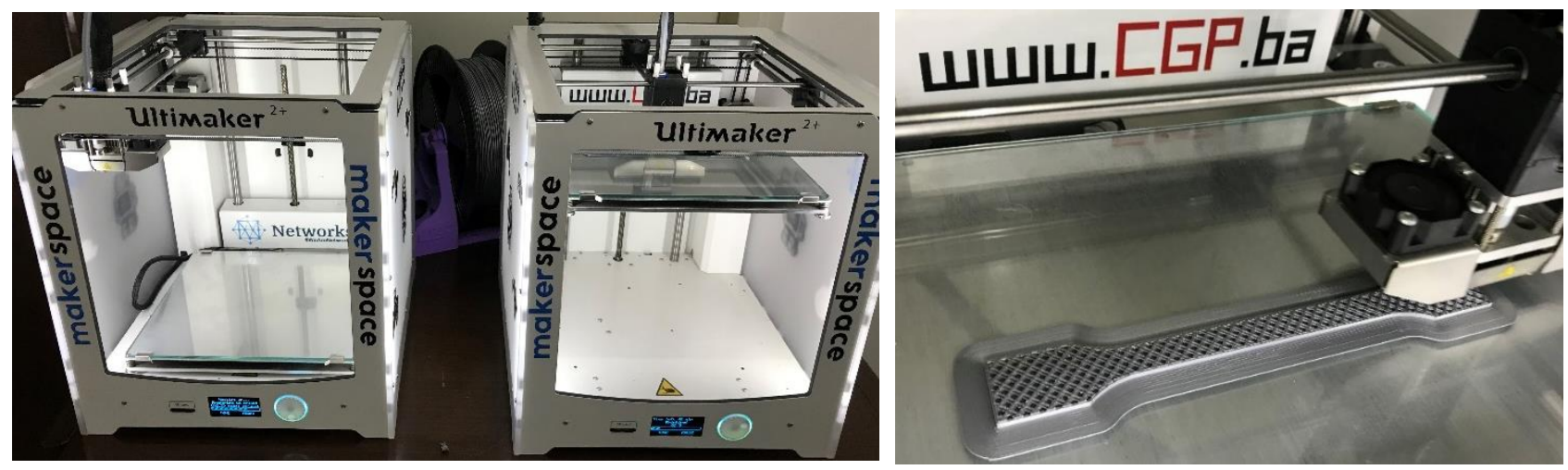

Fig. 5. 3D printing of dogbone-type specimen on Ultimaker 2+3D printer

After manufacturing, the tensile tests were carried out using a calibrated Shimadzu AGS-X machine, with a $100 \mathrm{kN}$ load cell. Specimens are tested according to ISO 527-2 standard, and with testing speed of $1 \mathrm{~mm} / \mathrm{min}$ (Fig 6.)
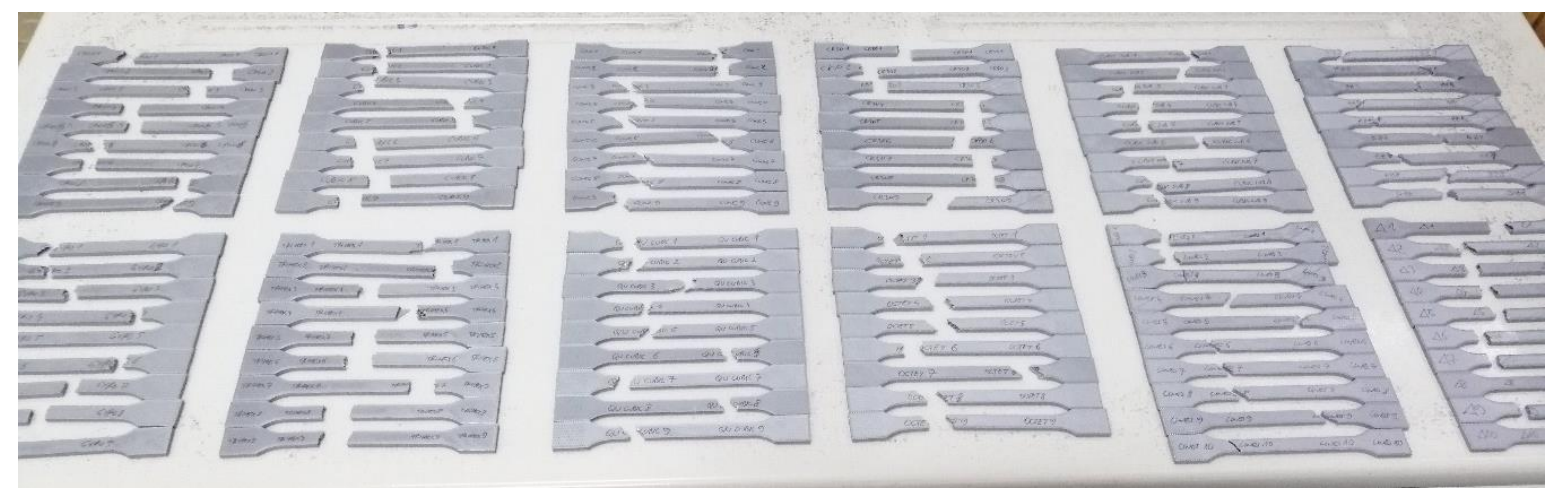

Fig. 6. 3D printed specimens after testing on Shimadzu AGS-X machine according to ISO 627-2 
Trapezium-X software is used for monitoring tensile properties results and drafting Stress-Strain diagrams (Fig 7.). Results are collected and analyzed with statistic methods and presented in further text.
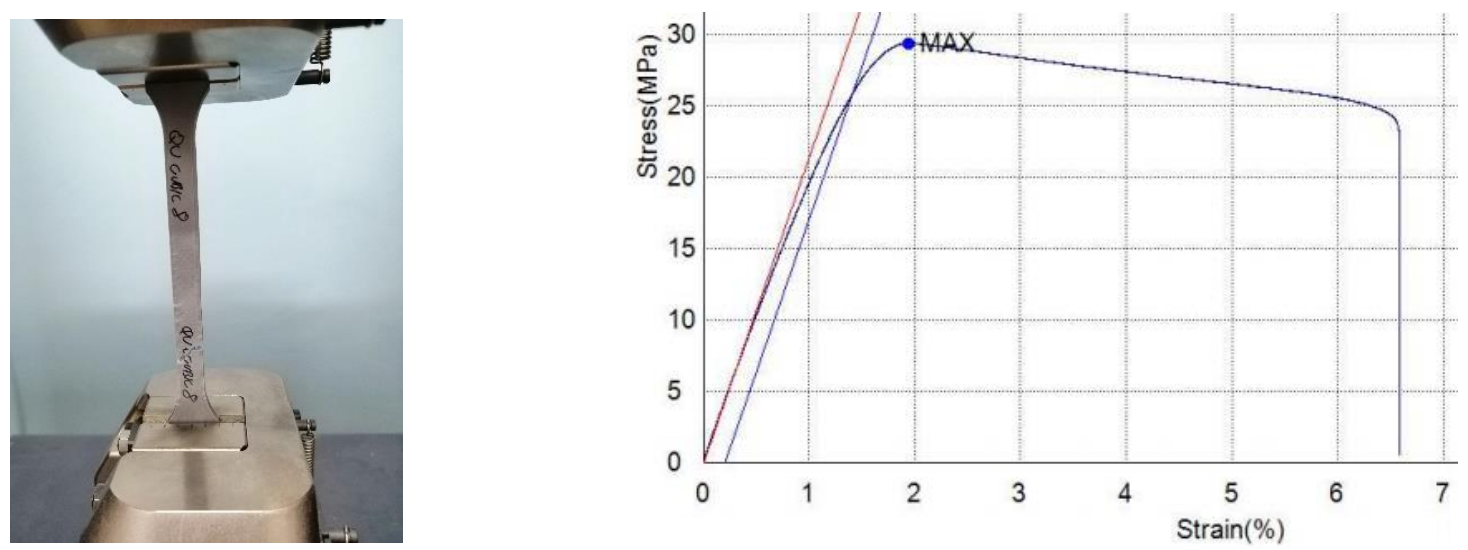

Fig. 7. Tensile testing and Stress-Strain diagram of Quarter Cubic specimen with $80 \%$ infill

\section{Results and discussion}

In this experiment total of 130 specimens of PLA material with different infill pattern and density are tested. Influence of infill pattern and density on ultimate tensile strength $\left(\mathrm{R}_{\mathrm{M}}\right)$ and yield strength $\left(\mathrm{R}_{02}\right)$ are tested, and all results are analysed in excel and presented in this paper.
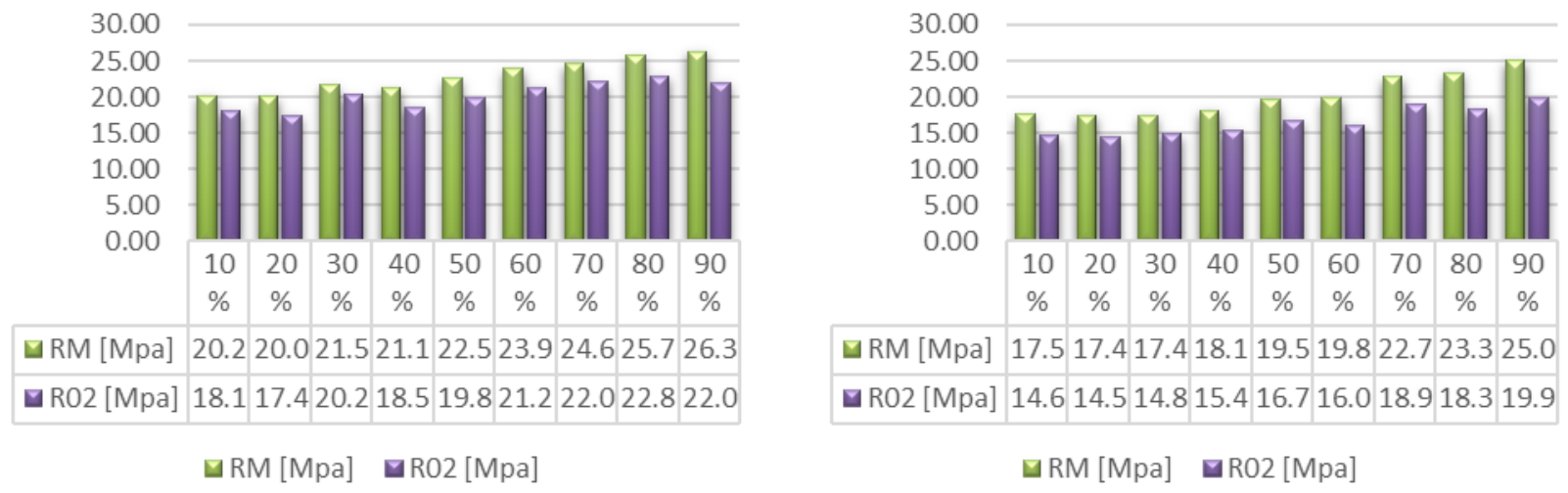

Fig. 8. Influence of infill pattern and density on $\mathrm{R}_{\mathrm{M}}$ and $\mathrm{R}_{02}$, "Grid" (left) and "Lines" (right) pattern

From Fig. 8. it can be seen that, for "Grid" infill pattern, with increase in the infill density from $10 \%$ to $90 \%$, both ultimate tensile strength for $30 \%$ and yield strength for $21 \%$ are increased. Also, for "Lines" infill pattern, both ultimate tensile strength for $42 \%$ and yield strength for $36 \%$ are increased.

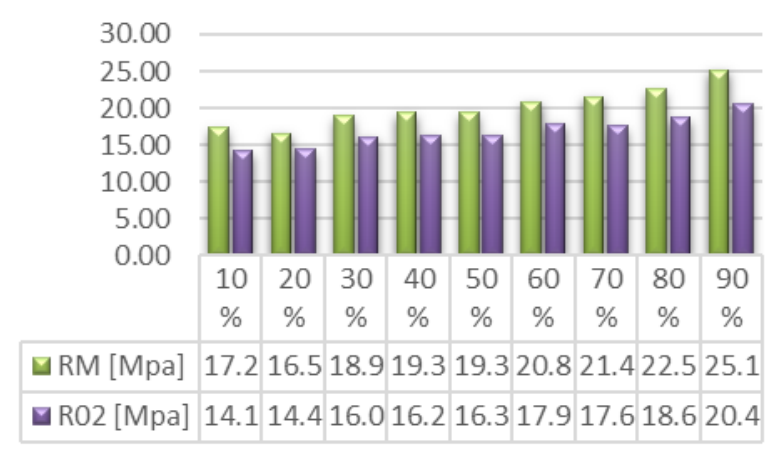

$\square \mathrm{RM}[\mathrm{Mpa}] \quad \boldsymbol{\mathrm { R } 0 2}[\mathrm{Mpa}]$

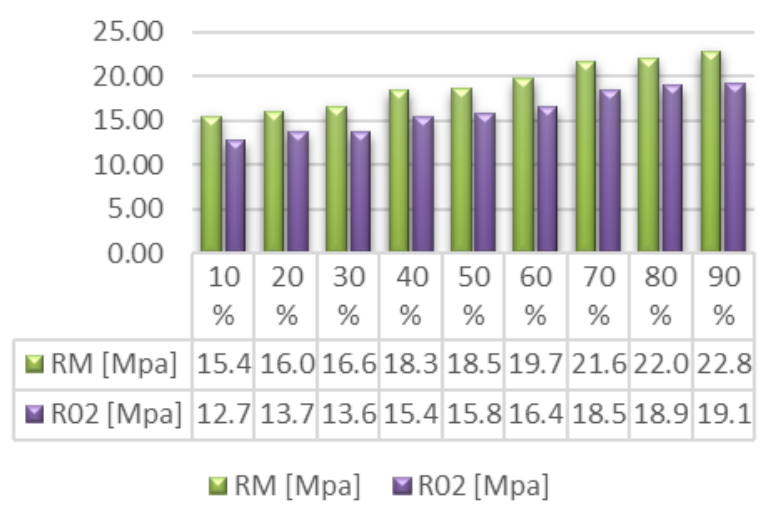

Fig. 9. Influence of infill pattern and density on $R_{M}$ and $R_{02}$, "Triangles" (left) and "Tri-Hexagon" (right) pattern 
From Fig. 9. it can be seen that, for "Triangles" infill pattern, with increase in the infill density from $10 \%$ to $90 \%$, both ultimate tensile strength for $45 \%$ and yield strength for $44 \%$ are increased. Also, for "Tri-Hexagon" infill pattern, both ultimate tensile strength for $48 \%$ and yield strength for $50 \%$ are increased.
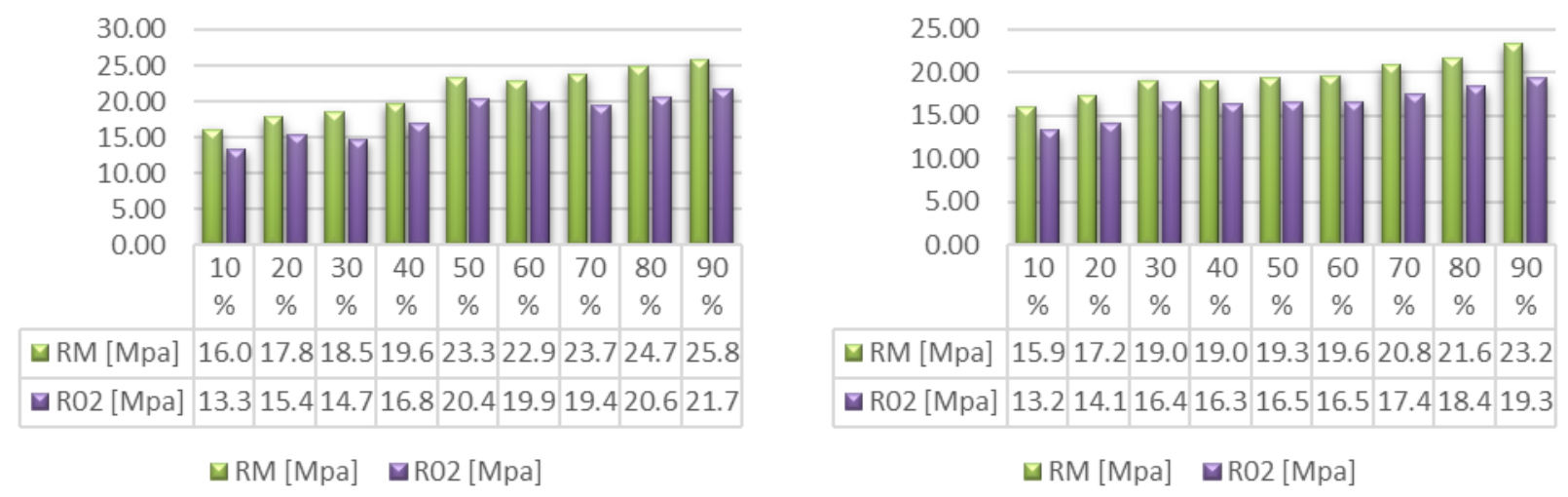

Fig. 10. Influence of infill pattern and density on $\mathrm{R}_{\mathrm{M}}$ and $\mathrm{R}_{02}$, "Cubic" (left) and "Cubic Subdivision" (right) pattern

From Fig. 10. it can be seen that, for "Cubic" infill pattern, with increase in the infill density from $10 \%$ to $90 \%$, both ultimate tensile strength for $61 \%$ and yield strength for $63 \%$ are increased. Also, for "Cubic Subdivision" infill pattern, both ultimate tensile strength for $45 \%$ and yield strength for $46 \%$ are increased.
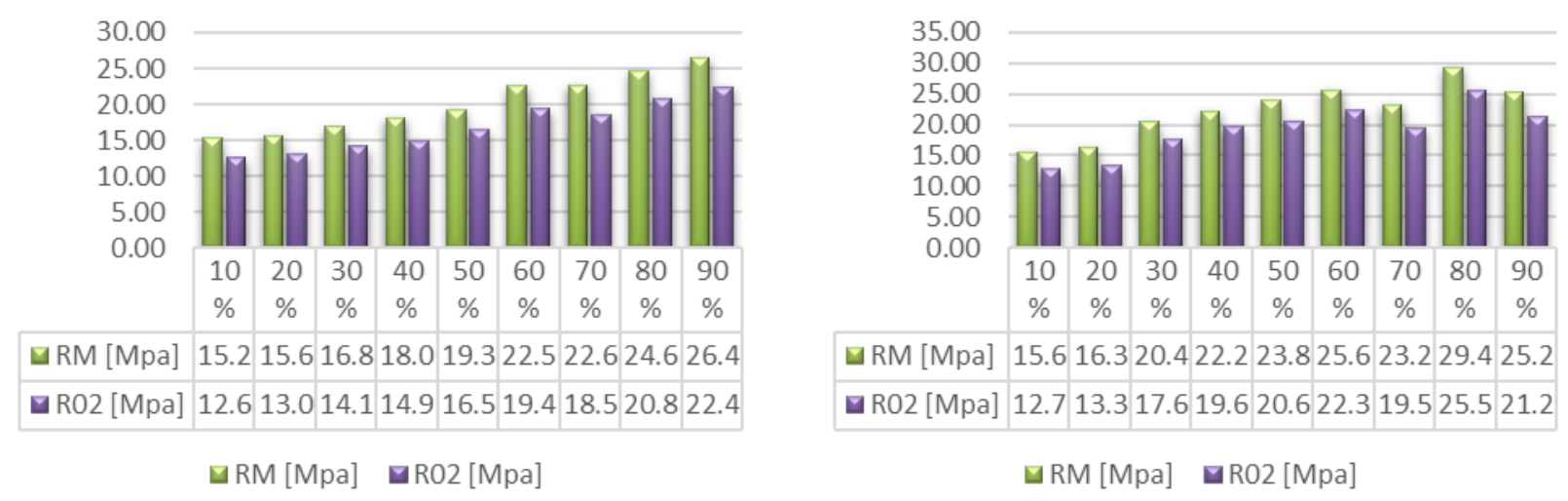

Fig. 11. Influence of infill pattern and density on $R_{M}$ and $R_{02}$, "Octet" (left) and "Quarter Cubic" (right) pattern

From Fig. 11. it can be seen that, for "Octet" infill pattern, with increase in the infill density from $10 \%$ to $90 \%$, both ultimate tensile strength for $73 \%$ and yield strength for $77 \%$ are increased. Also, for "Quarter Cubic" infill pattern, both ultimate tensile strength for $61 \%$ and yield strength for $66 \%$ are increased.
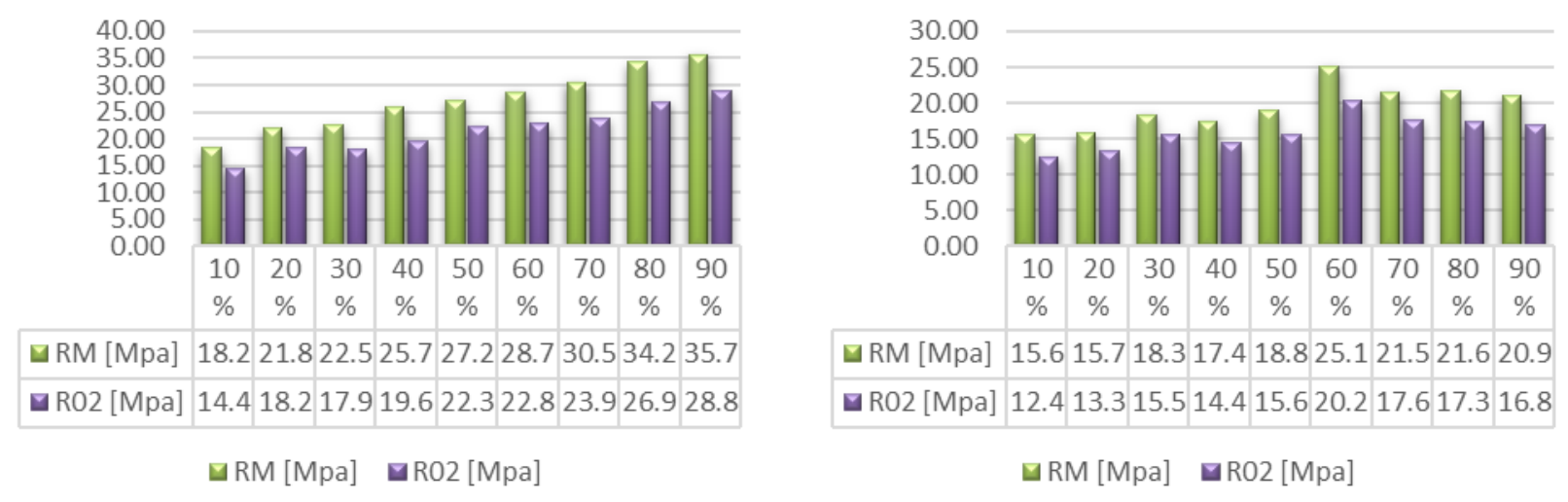

Fig. 12. Influence of infill pattern and density on $\mathrm{R}_{\mathrm{M}}$ and $\mathrm{R}_{02}$, "Concentric" (left) and "Zig Zag" (right) pattern 
From Fig. 12. it can be seen that, for "Concentric" infill pattern, with increase in the infill density from $10 \%$ to $90 \%$, both ultimate tensile strength for $96 \%$ and yield strength for $100 \%$ are increased. Also, for "Zig Zag" infill pattern, both ultimate tensile strength for $33 \%$ and yield strength for $35 \%$ are increased.
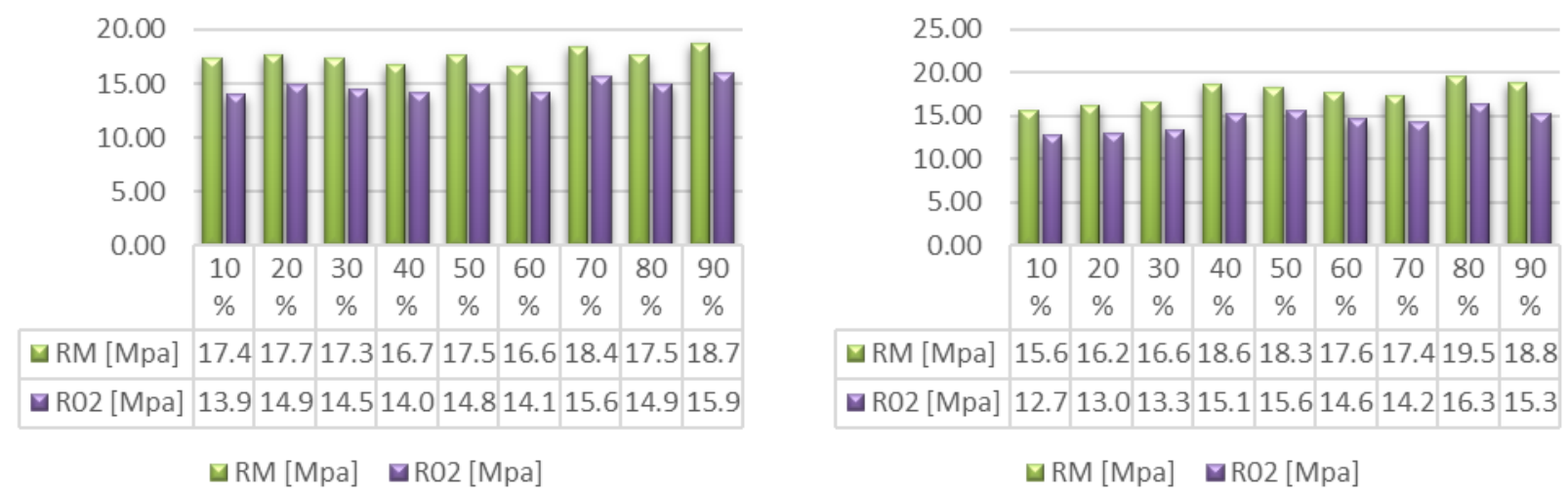

Fig. 13. Influence of infill pattern and density on $\mathrm{R}_{\mathrm{M}}$ and $\mathrm{R}_{02}$, "Cross" (left) and "Cross $3 \mathrm{D}$ " (right) pattern

From Fig. 13. it can be seen that, for "Cross" infill pattern, with increase in the infill density from $10 \%$ to $90 \%$, both ultimate tensile strength for $7 \%$ and yield strength for $14 \%$ are increased. Also, for "Cross 3D" infill pattern, both ultimate tensile strength for $20 \%$ and yield strength for $20 \%$ are increased.

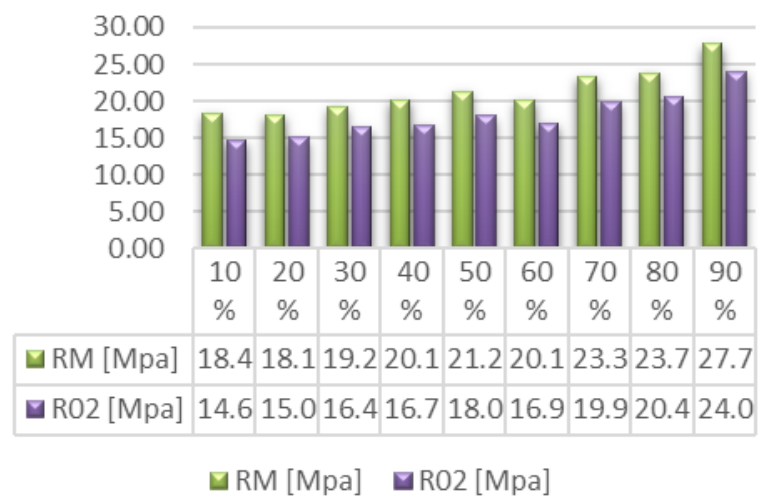

Fig. 14. Influence of infill pattern and density on $\mathrm{R}_{\mathrm{M}}$ and $\mathrm{R}_{02}$, "Gyroid" pattern

From Fig. 14. it can be seen that, for "Gyroid" infill pattern, with increase in the infill density from $10 \%$ to $90 \%$, both ultimate tensile strength for $50 \%$ and yield strength for $64 \%$ are increased.

Maximum ultimate tensile strength and yield strength for every infill pattern is presented in Fig. 15.

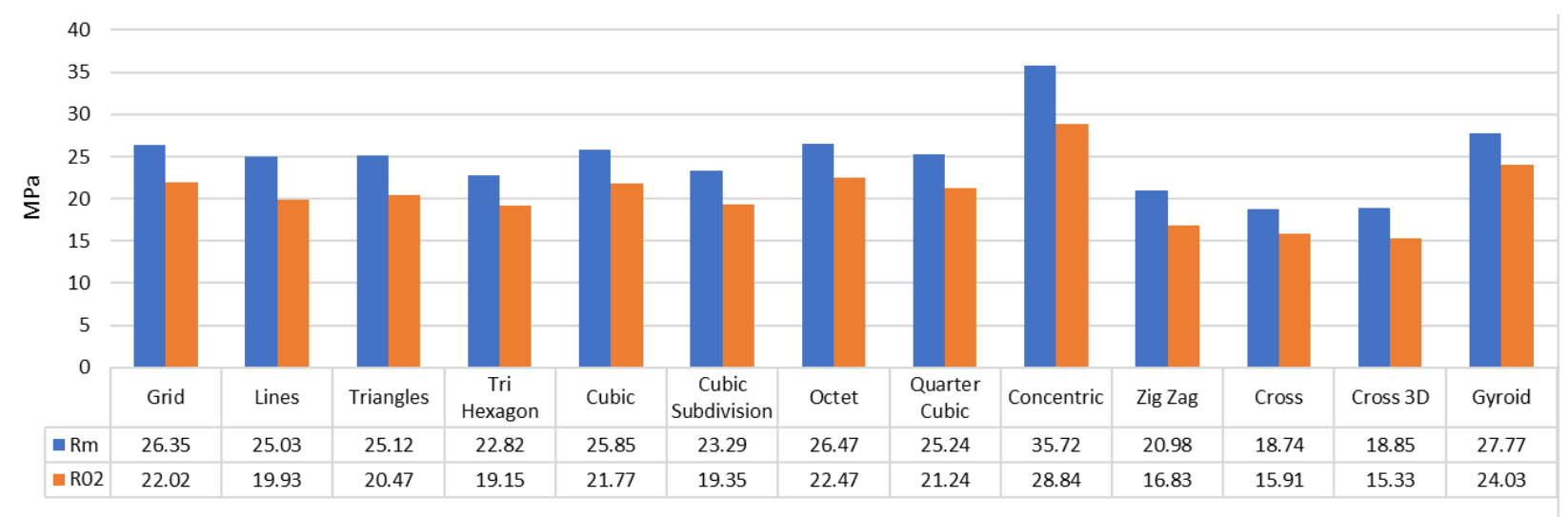

Fig. 15. Maximum ultimate tensile strength $\left(R_{M}\right)$ and yield strength $\left(R_{02}\right)$ for every infill pattern 
All infill patterns have maximum ultimate tensile strength and yield strength for $90 \%$ of infill (Fig. 15.). Results also showed that with $100 \%$ infill, PLA material have 42,15 MPa of ultimate tensile strength and 36,40 MPa of yield strength. If ultimate tensile and yield strength for all infill patterns with $90 \%$ infill are compared with $100 \%$ infill, it can be seen that difference is about $40 \%$. Also, the highest ultimate tensile strength and yield strength have "Concentric" infill pattern with $90 \%$ of infill.

\section{Conclusion}

One of the advantages of 3D printing FDM technology is that the products can be manufactured with different infill density. With this benefit, time and amount of material can be reduced and also costs of finished product.

After analysing the results obtained by tensile testing, it can be concluded that infill type and infill density have influence on ultimate tensile strength and yield strength. As the density increases from $10 \%$ to $90 \%$, the ultimate tensile strength and yield strength also increases for every types of infill pattern. Maximum strength is with $90 \%$ of infill.

So, if product need maximum tensile properties, it have to be 3D printed with $100 \%$ infill. Also, if designer want to save time and amount of 3D printed material, and decrease infill density from $100 \%$ to $90 \%$, product of PLA material will have reduced ultimate tensile strength and yield strength for $40 \%$. As for most first prototypes, the maximum strength of the product is not the most important, with those results mathematical model can me created, which can predict tensile strength depending on infill pattern and density.

Also, results are showing that "Concentric" infill pattern gives the highest ultimate tensile strength and yield strength. Comparing with $100 \%$ infill, with "Concentric" infill pattern of $90 \%$, ultimate tensile strength is reduced for only $15 \%$ and yield strength for $20 \%$, and printing time is reduced for $30 \%$.

In this paper, influence of infill pattern and density on material properties is examined only for tensile testing in one direction, and for one printing orientation. In future examinations, other factor should be considered as different printing orientation and testing in 3 directions. Also, influence of infill pattern and density on other mechanical properties (bending, pressure, hardness, etc.) should be examined. And with all this results, better "picture" of material behaviour with different infill pattern and density could be obtained, and that could be further used in FEM analyses.

\section{References}

[1] Pinero Vega D.; Batista Ponce M.; Valerga Pureta A. P.; Vazquez Martinez J. M. \& Fernandez Vidal S. P. (2018). A Comparison of Macro and Microgeometrical Properties of Specimens Made With a FDM Commercial Printer and its Opensource Retrofit Version, Proceedings of $29^{\text {th }}$ DAAAM International Symposium on Intelligent Manufacturing and Automation, Zadar, ISSN 1726-9679, ISBN 978-3-902734-20-4, Katalinic B. (Ed.), pp.11081115, Published by DAAAM International, Vienna, DOI: $10.2507 / 29^{\text {th }}$.daaam.proceedings. 158

[2] Polak R.; Sedlacek F. \& Raz K. (2017). Determination of FDM Printer Settings With Regard to Geometrical Accuracy, Proceedings of $28^{\text {th }}$ DAAAM International Symposium on Intelligent Manufacturing and Automation, Zadar, ISSN 1726-9679, ISBN 978-3-902734-11-2, Katalinic B. (Ed.), pp.0561-0566, Published by DAAAM International, Vienna, DOI: 10.2507/28th.daaam.proceedings.079

[3] Hajdarevic S.; Obucina M.; Mesic E. \& Martinovic S. (2018). Stress and Strain of the Frontal Parallel Joints With $3 \mathrm{D}$ Printed Connectors, Proceedings of $29^{\text {th }}$ DAAAM International Symposium on Intelligent Manufacturing and Automation, Zadar, ISSN 1726-9679, ISBN 978-3-902734-20-4, Katalinic B. (Ed.), pp.0361-0368, Published by DAAAM International, Vienna, DOI: $10.2507 / 29^{\text {th }}$.daaam.proceedings.052

[4] Farhad M. O.; TahseenFadhil A. \& Hind B. A. (2018). Influence of Process Parameters on Mechanical Properties and Printing Time of FDM PLA Printed Parts Using Design of Experiment. Journal of Engineering Research and Applications, Vol. 8, No. 7, (July 2018) page numbers (65-69), ISSN: 2248-9622

[5] Baich L. (2016). Impact of Infill Design on Mechanical Strength and Production Cost in Material Extrusion Based Additive Manufacturing, Master of Science in Engineering Thesis, Industrial and Systems Engineering Program, Youngstown State Univeristy, Youngstown, Ohio - USA

[6] Farbman D. \& McCoy C. (2016). Materials Testing of 3D Printed ABS and PLA Samples to Guide Mechanical Design, Available from: https://www.researchgate.net/publication/308709141_Materials_Testing_of_3D_Printed_ABS_and_PLA_Sample s_to_Guide_Mechanical_Design Accessed: 2019-6-7

[7] Cekic A.; Begic-Hajdarevic D.; Muhamedagic K. \& Guzanovic N. (2018). Experimental Investigations of Process Parameters Influence on Dimensional Accuracy and Mechanical Properties of FDM Manufactured Parts, Proceedings of $29^{\text {th }}$ DAAAM International Symposium on Intelligent Manufacturing and Automation, Zadar, ISSN 1726-9679, ISBN 978-3-902734-20-4, Katalinic B. (Ed.), pp.0210-0214, Published by DAAAM International, Vienna, DOI: $10.2507 / 29^{\text {th }}$.daaam.proceedings.030

[8] Fernandez-Vicente M.; Calle Wilson.; Ferrandiz S. \& Conejero A. (2016). Effect of Infill Parameters on Tensile Mechanical Behaviour in Desktop 3D Printing. 3D Printing and Additive Manufacturing, Vol. 3, No. 3, (September 2016) page numbers (183-192), ISSN: 2329-7662 
[9] TahseenFadhil A.; Farhad M. O. \& Hind B. A. (2017). Effect of Infill Parameter on Compression Property in FDM Process. Journal of Engineering Research and Applications, Vol. 7, No. 10, (October 2017) page numbers (16-19), ISSN: 2248-9622

[10] Alvarez K. L. C.; Lagos R. F. C. \& Aizpun M. (2016). Investigating the Influence of Infill Percentage on the mechanical Properties of Fused Deposition Modelled ABS Parts. Ingenieria e Investigacion, Vol. 36, No. 3, (December 2016) page numbers (110-116), DOI: http://dx.doi.org/10.15446/ing.investig.v36n3.56610

[11] Akhoundi B. \& Behravesh A. H. (2018), Effect of Filling Pattern on the Tensile and Flexural and Mechanical Properties of FDM 3D Printed Products, Experimental Mechanics an International Journal, Vol. 11340, December 2018, ISSN 0014-4851

[12] Jap N. S. F.; Pearce G. M.; Hellier A. K.; Russell N.; Parr W. C. \& Walsh W. R. (2019), The Effect of Raster Orientation on the Static and Fatigue Properties of Filament Deposited ABS polymer, International Journal of Fatigue, Vol. 124., July 2019, 328-337, ISSN 0142-1123

[13] Floor J. (2015). Getting a Grip on the Ultimaker 2 - Tensile Strength of 3D Printed PLA: A Systematic Investigation, Delft University of Technology - Faculty of Industrial Design Engineering \& Ultimaker B.V., 20151215 